REVISTA DE LITERATURA E CULTURA RUSSA

\title{
Tchernichévski: entre o determinismo e a revolução
}

\section{Chernyshevsky: Between the Determinsm and the Revolution}

Autor: Paulo Cesar Jakimiu Sabino Edição: RUS Vol. 11. № 16 Data: Setembro 2020 


\section{Tchernichévski: entre o determinismo e a revolução}

\section{Paulo Cesar Jakimiu Sabino*}

Resumo: 0 artigo a seguir versa sobre o filósofo russo N. Tchernichévski. Mais precisamente, nosso interesse é saber até que ponto é justo considerar apenas o aspecto racionalista e determinista de sua obra - algo muito comum quando a leitura do escritor é realizada à luz de outras interpretações já consagradas, como a de Dostoiévski. Nesse sentido, realizamos o seguinte caminho para tornar compreensível a ideia: (i) exposição da teoria ética de Tchernichévski em "O Princípio Antropológico em Filosofia"; (ii) como essa teoria constrói os personagens do romance $O$ que fazer?; (iii) por fim, analisamos um personagem em especial: Rakhmetov.

\begin{abstract}
The following article is about the Russian philosopher $\mathrm{N}$. Chernyshevsky. To be precise, our interest is to comprehend to what extent it is fair that one considers only the rationalistic and deterministic characteristics of his work something one has come to expect when the reading is in the light of the most acclaimed interpretations, as Dostoevsky's. In this respect, the article followed a particular path to make the idea more understandable by: (i) exposing Chernyshevsky's ethical theory in "The Anthropological Principle in Philosophy"; (ii) discussing how this theory build the characters of the novel What is to be done?; (iii) and analyzing one of the characters in particular: Rakhmetov.
\end{abstract}

Palavras-chave: Racionalismo; Sensibilidade; Revolução; "Nova Gente” Keywords: Rationalism; Sensibility; Revolution; "New People” 


\section{Introdução}

* Doutorando em Filosofia na Universidade Federal do Paraná (UFPR), Faculdade de Filosofia Ciências e Letras. Autor do livro Nietzsche: da filosofia do trágico à filosofia trágica, ou o criar como afirmação da vida; https:// orcid.org/0000-0002-7811-672X; pcjsabino1@yahoo.com.br
Nikolai Gavrilovitch Tchernichévski é um autor russo pouco conhecido entre os brasileiros. Seu livro mais importante, o romance $O$ que fazer? recebeu uma tradução para o português apenas em 2015. ${ }^{1}$ Contudo, Tchernichévski entra para a história como um dos mais importantes membros da intelligentsia esclarecida e como um dos principais influenciadores do pensamento revolucionário que tomou conta da Rússia na segunda metade do século XIX.

O seu pensamento é formado sob influência do materialismo filosófico, do socialismo utópico e do utilitarismo. Apesar de uma formação sólida, não ficou livre de controvérsias. Segundo James Scanlan, enquanto alguns intérpretes o consideravam materialista sem maiores problemas - caso de Plekhanov e Lênin -, outros afirmavam que seu materialismo era de um tipo "primitivo e cru", "ingênuo" e "lamentável" - como foi o caso do filósofo russo Nikolai Berdiaev. ${ }^{2}$ Essas críticas sobre um pensamento não são meras difamações, mas é digno de nota que tais "inconsistências" podem ser consequências das circunstâncias sob as quais escreveu: como muitos intelectuais da época, estava sob vigilância da censura tsarista, por isso, precisava expor algu mas ideias nas entrelinhas, evitando alguns termos e nomes que eram proibidos - por exemplo, a palavra "revolução" não aparece uma vez sequer no romance, e era proibido pela censura o nome de Ludwig Feuerbach, que foi a principal influência de Tchernichévski. Inclusive, seu romance foi escrito no cárcere, porque em 1862 foi preso de maneira bastante questionável. ${ }^{3}$

1 No Brasil, pela editora Prismas com tradução de Angelo Segrillo. Em 2017, o livro foi adaptado para o português de Portugal por Ana Salgado e publicado pela editora Guerra \& Paz. Esta última é a edição utilizada para 0 artigo.

2 Cf. SCANLAN, 1970, p. 66.

3 Em 7 de julho de 1862 Tchernichévski é preso na fortaleza de São Pedro e São Paulo, ficando detido por oito meses sem receber uma acusação formal. Em 1864 sua sentença foi dada e ele considerado criminoso do Estado, sendo levado aos campos de trabalho na região da Sibéria. Devido às tentativas para libertá-lo, foi deslocado para diferentes regiões. Apenas em junho de 1889 foi liberado pelo governo para viver com sua família em Sarátov, onde permaneceu até a sua morte quatro meses depois, em 17 de outubro de 1889 (Cf. 
As dificuldades para compreender sua obra não se encerram por aqui. Apesar de $O$ que fazer? ter recebido uma recente tradução para o português, outros textos ainda permanecem inacessíveis ao leitor brasileiro. De modo que não é estranho ter o primeiro contato com sua obra de maneira indireta. Por exemplo, através da crítica de Dostoiévski estabelecida em Memórias do subsolo, cuja interpretação pode sugerir que Tchernichévski era um racionalista e determinista exacerbado - e como estamos mais habituados ao autor de Crime e castigo, acabamos por tomar acriticamente a obra tchernichévskiana.

\section{Determinismo e ética em "O Princípio Antropológico na Filosofia"}

Compreender o texto de um autor pelo seu contexto, em geral, facilita o processo de aprendizagem de seu pensamento. No entanto, é inviável traçar aqui todo um panorama do longo e complexo pensamento social russo desde o século XVIII. ${ }^{4}$ Uma breve consideração, por sua vez, ajuda a tornar mais compreensível o assunto: Tchernichévski pertence a uma classe de revolucionários da intelligentsia russa que ficou conhecida como "Filhos", graças ao romance de Ivan Turguêniev - também conhecida como geração dos sessenta, que era marcada pela atitude radical em relação à política russa. Essa geração entrava em conflito com a dos anos quarenta, os "Pais", de cunho liberal e reformista. Essa postura radical dos "Filhos" é uma consequência direta dos fracassos dos modelos europeus de reformas liberais na Rússia. ${ }^{5}$ Os intelectuais de ambas as gerações buscavam inspiração no ocidente - por isso, ficaram conhecidos como ocidentalistas -, mas a geração dos quarenta estava mais comprometida com as filosofias idealis-

DOMINGUES, 2015, p. 87-90).

4 Sobre isso, cf. WALICKI, 1979, que aborda esse processo histórico em A history of russian thought.

5 Desde o projeto de modernização de Pedro, o Grande, a Rússia passou por uma série de tentativas de reestruturar à ordem social. Entre essas tentativas malsucedidas, podemos destacar a "Revolta Dezembrista" de 1825, que foi um duro golpe nas aspirações liberais dos intelectuais da época. 
tas do século XVIII. Por consequência, a geração dos sessenta buscava alternativas, tendo em vista oferecer soluções mais práticas às questões sociais da Rússia, pois, embora compartilhassem dos mesmos ideais como "progresso" e "liberdade", os meios para alcançá-los eram outros. Em suma: o pensamento tchernichévskiano faz oposição a muitas das filosofias que inspiraram a geração dos "Pais", porque eram especulativas e/ ou idealistas.

Entre os textos mais importantes de Tchernichévski está o artigo intitulado "O Princípio Antropológico na Filosofia" de 1861 - escrito como resposta direta ao "Ensaio sobre os Problemas da Filosofia Prática" de Piótr Lavróv ${ }^{6}$ - no qual faz duras críticas ao pensamento idealista. É nesse artigo que formula sua teoria ética a partir da reorganização de conceitos antes apropriados de maneira inadequada pelos filósofos idealistas; entre eles, está o conceito de razão.

Na filosofia de Tchernichévski, a capacidade racional do ser humano poderia viabilizar a construção de uma sociedade justa e perfeita, mas, segundo sua interpretação, a filosofia idealista não formulou adequadamente um conceito de razão, porque para os idealistas a razão agiria em linha estritamente abstrata. É a partir desse parâmetro que irá contrariar as teses de dois autores mencionados no ensaio de Lavróv: Jules Simon e John Stuart Mill. ${ }^{7}$

Na perspectiva de Tchernichévski, Jules Simon sustentava uma relação entre intelectual e sociedade totalmente absurda. De acordo com Simon, seria uma novidade escrever um livro sem qualquer relação com a realidade política atual, defendendo a tese de que uma teoria política não precisaria estar comprometida com as circunstâncias concretas do real. Tchernichévski pensa o contrário, porque acredita que toda

6 Filósofo russo, Lavróv tentava através de um estilo eclético reconciliar a filosofia materialista com o pensamento kantiano. Por esse motivo, mesmo considerando seu conterrâneo um progressista, Tchernichévski acreditava que ele jamais poderia atingir o verdadeiro progresso já que não aderiu à filosofia adequada, isto é, ao materialismo livre de intervenções idealistas.

7 Tchernichévski ainda estabelece um diálogo com Proudhon no "Princípio". Porém, os temas são menos importantes para a proposta do trabalho apresentado, e, sendo assim, esse diálogo não será abordado. 
tentativa de teorizar sobre política sem considerar os eventos sociais seria pouco proveitosa para promover transformações na sociedade, uma vez que as "teorias políticas, e todas as doutrinas filosóficas em geral, foram sempre criadas sob a poderosa influência da situação social à qual elas pertenciam"8, isto é, todo filósofo era representante de um partido ou corrente política de sua realidade social. Por exemplo, Locke era um Whig, Hobbes um absolutista, Rousseau um democrata. ${ }^{9}$ Tais filiações podem ser questionáveis, mas o mais importante é observar a ideia proposta pelo argumento: se toda teoria é influenciada pelo ambiente político ao qual pertence, então, aquelas que fossem puramente abstratas somente poderiam elaborar pensamentos fantásticos - entenda-se, idealista sobre a realidade, sem qualquer serventia à luta política, afastando o pensador de encontrar soluções práticas. Esse tipo de pensamento seria conduzido por filósofos alienados de sua realidade, filósofos de cátedra: "Para Tchernichévski, a ciência e a filosofia até o final do século XVII estavam nas mãos de filósofos de cátedra, que cultivavam apenas a razão pura e o pensamento abstrato, presos ao método escolástico" ${ }^{10}$ Esse modelo oferece uma filosofia que jamais atinge a essência da realidade, já que é estruturada exclusivamente sobre pilares abstratos da razão, desconsiderando as condições concretas e históricas do real. Os resultados de tais filosofias seriam completamente desinteressantes para fomentar a discussão política, já que pouco poderiam oferecer ao povo:

A Europa ocidental é muito rica em experimentos políticos, em teorias políticas, diz o senhor Lavróv; mas aonde ela chegou depois de pagar por tantos experimentos e de exercer tanto esforço mental para avaliá-los? Apenas a um sentimento de descontentamento com o presente e de medo pelo futuro. ${ }^{11}$

Nesse trecho, o autor não deixa explícito quais experimentos foram esses, mas é muito provável que se refira às conse-

8 TCHERNICHÉVSKI, 2002, p. 50, tradução do autor.

9 Ibidem, p. 50-51.

10 DOMINGUES, 2015, p. 121

11 TCHERNICHÉVSKI, 2002, p. 57, tradução do autor. 
quências do pensamento político burguês. Após a Revolução Francesa, que proporcionou benefícios importantes à classe, a burguesia pouco fez pelos proletariados, algo que ficou evidente pelas jornadas revolucionárias de 1848 , fazendo transparecer como as revoluções burguesas pautadas nas ideias da filosofia especulativa não favoreciam a igualdade de classes, porque conduziam seu pensamento ignorando o desenvolvimento histórico.

Isso nos leva à crítica ao economista britânico John Stuart Mill. Tchernichévski acusa Mill de um "racionalismo exacerbado" que impede a efetivação do progresso ético e político da sociedade, algo que seria comprovado pelas próprias ações políticas do economista britânico. ${ }^{12}$ Segundo Domingues ${ }^{13}$, Mill defendeu a ampliação do voto aos trabalhadores do gênero masculino e feminino, mas esbarrou na questão do voto secreto, recuando em sua posição progressista. Tchernichévski conclui que ele teria agido desse modo porque desejava que o desenvolvimento da vida social seguisse linhas absolutamente racionais, ${ }^{14}$ mas "isso não acontece em assuntos importantes nem na vida individual nem na vida de uma nação. Apenas em assuntos menos importantes as coisas são feitas de maneira fria, calma, deliberada e racional" ${ }^{15}$ Por isso, se a filosofia não considerar as condições concretas da realidade - que não obedecem a uma lógica racional - ela jamais alcançaria a essência do objeto/fenômeno sob investigação:

Para Tchernichévski, o desenvolvimento histórico não obedeceria puramente à razão e estaria sujeito a movimentos convulsivos - as grandes transformações históricas nos quais a razão operaria apenas lateralmente às fortes paixões individuais ou de classe. Nestes momentos, os fatos afetariam os sentidos de maneira concreta, de uma forma que as teorias e ideias abstratas não poderiam afetar [...]. 0 que ligaria o conceito abstrato ao "objeto tangível" ou ao fato concreto em si seria a relação e o interesse real - material do pensador com aquele evento. Portanto, a teoria ou a história não se confirmariam por si, em um esquema metafísico, mas em relação com as "circunstâncias dadas", que colocariam o pensamento e a ação dos indivíduos e grupos sociais em choque ou em consonância com a realidade concreta, a 
depender de seus interesses individuais ou de classe $^{16}$

Fica mais nítida a diferença entre uma razão "abstrata" tal como a dos idealistas e a razão tchernichévskiana, de cunho materialista: esta última não está isolada das circunstâncias históricas que estão sob constante influência das paixões. Diferente de alguns autores que acreditavam serem as paixões o obstáculo que comprometiam a veracidade de uma teoria, o pensador russo não acredita que elas falseiam ou obscurecem o conhecimento; pelo contrário, torna-se indispensável que o pensador saiba avaliá-las corretamente. O seu critério de verdade é outro: "como se prenunciasse: 'o critério da verdade é a prática' e propusesse uma relação indissociável entre o agir o pensar, entre política e filosofia, assentando as bases do seu materialismo histórico". ${ }^{17}$ Uma teoria é verdadeira quando pode ser posta em prática e as paixões que influenciam o desenvolvimento histórico são apenas consequências diretas e intrínsecas de um fenômeno social, sem qualquer relação direta com a verdade deste fenômeno.

A razão concreta é moldada pelo processo histórico e através de suas condições materiais. No entanto, isso não significa dizer que a razão atua de acordo com as paixões, mas, como Domingues, supracitado, salientou: ela opera lateralmente, tentando articular as paixões presentes nos fenômenos sociais a fim de impor uma finalidade objetiva ao processo passional da história - que em geral é caótico e confuso: uma revolução, por exemplo, não é resultado exclusivo das paixões, uma vez que elas são orientadas para um fim estabelecido racionalmente; um bom exemplo é a revolução russa que arquitetou a sociedade dentro de uma lógica comunista.

O propósito do materialismo é a união entre força e maté$r i a^{18}$ na qual o ser humano é visto como uma unidade orgâ-

16 DOMINGUES, 2015, p. 108.

17 Ibidem, p. 110.

18 Esses dois termos, não por acaso, remetem ao título da obra do pensador, Ludwig Büchner - Kraft ["força"] und Stoff ["matéria"], um dos mais importantes influenciadores do materialismo russo no século XIX ao lado de Carl Vogt e Jacob Moleschott. Entre meados de 1840 e de 1850, eles escreveram artigos que ficaram populares - não apenas na Rússia - no qual realizavam uma espécie de fusão entre química, fisiologia com ideias políticas 
nica. Para Tchernichévski, uma filosofia progressista está de acordo com a ideia já provada pelas observações dos fisiologistas, médicos e zoologistas de que o ser humano não pode ser dividido entre alma e corpo. Partindo dessa premissa, estava convicto de que era impossível progredir sem o apoio das ciências exatas, sendo imprescindível adotar um novo modelo de pensamento para investigar o ser humano tal como ele é. Assim, irá defender a tese de que a filosofia, em diversos campos do conhecimento, precisava aderir ao método das ciências exatas. Para Tchernichévski, considerando os avanços científicos, não faria mais sentido tratar dos problemas humanos senão pela ótica da ciência e da razão concreta.

Na segunda metade do seu artigo, realiza uma exposição acerca da diferença entre ciências exatas - matemática, física, química, etc., que também chamamos de ciências naturais - e aquelas que ele denominava de ciências morais - nossas "ciências humanas", como a filosofia, história, psicologia e a ética:

A palavra "ciência" [Science] em inglês não cobre de forma alguma todos os ramos do conhecimento que esse termo abrange entre nós e entre outras nações continentais. No inglês, ciência significa: matemática, astronomia, física, química, botânica, zoologia, geografia - aqueles ramos do conhecimento que nós chamamos de "exatas" e aquelas de natureza semelhante. Mas eles não aplicam esse termo à história, psicologia, filosofia moral ou metafísica. ${ }^{19}$

A diferença entre essas duas áreas é elucidada pelo filósofo de maneira bastante simples: enquanto as ciências exatas chegam a resultados unívocos e amplamente aceitos pelo senso comum e pela comunidade científica, as ciências morais oferecem apenas um apanhado de conclusões díspares, portanto, sem uma conclusão vencedora capaz de pôr fim à discussão ou ao problema abordado. 0 método das ciências exatas deveria, assim, ser unido às ciências humanas:

Não faz muito tempo que as ciências morais não poderiam possuir o conteúdo que justificasse o título de ciência

(Cf. FREDE, 2011, p. 140-1).

19 TCHERNICHÉVSKI, op. cit., p. 88. 
que carregavam, e os ingleses tinham toda razão em, então, privá-las do título que não mereciam. A situação hoje mudou consideravelmente. As ciências naturais já se desenvolveram a tal ponto que também fornecem material para a solução exata dos problemas morais. Todos os pensadores progressistas entre os que estudam as ciências morais começaram a resolver esses problemas com o auxílio de métodos precisos semelhantes àqueles pelos quais os problemas das ciências naturais estão sendo resolvidos. ${ }^{20}$

Tchernichévski não ignorava que o ser humano possuía duas categorias de fenômenos: os de ordem material - ele come, anda - e os de ordem moral - ele pensa, sente, deseja. ${ }^{21}$ Porém, de acordo com sua interpretação, uma vez que as ciências exatas revelaram que o ser humano, compreendido como uma unidade orgânica, é determinado pelas mesmas leis que determinam a natureza, então até mesmo os fenômenos morais nada mais são do que expressões de forças governadas por essas leis. Logo, ainda que existam duas categorias, elas estão submetidas às mesmas leis da natureza.

Dentre estas, uma é destacada por ser fundamental: "Sabe-se, definitivamente, por exemplo, que todos os fenômenos do mundo moral se originam um do outro e de circunstâncias externas em conformidade com a lei da causalidade". ${ }^{22}$ No campo da ciência, a causalidade garante o caráter provável dos fatos, o que permite antecipar sua conclusão. Logo, todo fenômeno físico ou moral parte de uma causa e possui um efeito, e, nessa lógica, é possível obter um conhecimento de maneira mais segura, isto é, que não seria apenas um conjunto emaranhado de opiniões.

Como é apontado por Walicki, os argumentos apresentados no "Princípio" serviriam para preparar o terreno à teoria ética do filósofo, o "egoísmo racional", "que era baseado na premissa de que - por qualquer intepretação - o princípio norteador da conduta é o egoísmo". ${ }^{23} \mathrm{Na}$ visão de Tchernichévski, nós

20 Ibidem, p. 92

21 Cf. Ibidem, p. 72

22 Ibidem, p. 94

23 WALICKI, 1979, p. 195. 
aprendemos, por experiência, que o homem pensa primeiro em si mesmo, e disso se segue a premissa básica da sua ética: o egoísmo é a causa das ações humanas. Esse egoísmo é ilustrado pelo par "prazer-dor": todo indivíduo buscará prazer e tentará evitar a dor. Essa questão não é tão simples e não podemos imediatamente associá-la a uma ética hedonista, porque o filósofo considera o ser humano um "ser social", e, portanto, sempre que age racionalmente tentará alcançar o bem-comum, pois o bem-estar social seria o seu bem-estar. Nessa lógica, será de interesse do indivíduo egoísta o bem-estar social, mesmo que para isso deva tolerar algum desprazer ou sofrimento, em prol desse prazer maior:

Obviamente, a razão deveria ser aplicada para ponderar as sensações deflagradoras de prazer e dor. Inclusive poderia ser admitido a economia de algum prazer maior ou sofrimento de alguma dor em nome de um prazer maior. Aplicando-se o critério da razão e através de sucessivas derivações lógicas, os utilitaristas deduziram que o prazer maior, ou o bem maior, é a felicidade da humanidade promovida a partir da aplicação plena da razão em todas as atividades humanas. O bem maior seria, portanto, aquele útil, a própria utilidade. Tratar-se-ia, assim, de um egoísmo racional, porque comprometido com a maior felicidade da humanidade e apoiado, para tal, na razão e na ciência. ${ }^{24}$

Estaria comprovado ao filósofo, através da experiência e aferível à luz da razão, que todos agimos por interesses egoístas, mas quando se compreende que o maior prazer individual é fornecido através de uma sociedade justa e igualitária, o indivíduo não hesitaria em abdicar do prazer imediato, sendo naturalmente levado a lutar por essa sociedade. A ética de Tchernichévski é uma economia de afetos organizados pela razão em que os interesses egoístas - a causa - podem fazer nascer uma sociedade igualitária - efeito. De tal maneia que não haveria conflito entre interesses individuais e coletivos quando o ser humano fosse esclarecido, pois estaria apenas agindo de acordo com sua própria natureza. Mas como explicar que isso não aconteça? Que o indivíduo aja apenas por imediatismo? Resposta: porque ele não foi esclarecido e, consequentemente,

24 DOMINGUES, 2015, p. 199. 
age de maneira irracional, isto é, contrariando as leis que deveriam governar sua natureza humana.

Já foi estabelecido que, para Tchernichévski o desenvolvimento histórico é afetado pelas paixões. Consequentemente, este desenvolvimento não será racional em sua essência; todavia, isso não o impede de ser racional mediante esforço humano. Esforço que se faz necessário, porque em uma sociedade irracional o ser humano não consegue agir eticamente: as circunstâncias externas afetam nosso comportamento, afinal de contas, o princípio de utilidade não será posto em prática se $o$ agente for coagido por forças estranhas a ele. Apesar de nossas ações serem motivadas por um princípio interno/natural, isso não significa que sejamos seres "éticos por natureza". A ação é motivada internamente, mas o comportamento ético é moldado também por circunstâncias externas. Segundo Domingues,

[...] a Ética possui uma origem externa ao homem, isso significa que ela é apreensível e transmissível. A transformação ética não depende - puramente - de mudanças subjetivas individuais, mas de alterações nas circunstâncias externas que operariam em cascatas sobre a Ética [...] O ser ético constituir-se-ia em uma sociedade ética ou na tentativa racional de construi-la. ${ }^{25}$

Portanto, em uma sociedade esclarecida não haveria qualquer conflito ou dilema ético, permitindo que a ação fosse coordenada apenas de acordo com as leis que governam nossa natureza, uma vez que nossos interesses não seriam confusos, o que significa dizer que não pensaríamos nos interesses particulares, fontes de prazer imediato, como os mais salutares. Tal conclusão só acontece quando estamos ofuscados por outras visões de mundo que não se orientam pela ciência e pela razão. Observa-se que esse pensamento, diferente daquele de Mill, não se orienta apenas pela razão abstrata, pois considera as circunstâncias externas concretas do real e como elas afetam nosso comportamento ético.

Uma sociedade ética depende de uma ação política transformadora. Porém, há um paradoxo: essa ação ética só é possível 
em uma sociedade ética, por outro lado, para atingir essa sociedade é necessário alguém de poderosa conduta ética. Tal paradoxo está presente no romance $O$ que fazer? no qual o autor ilustra sua perspectiva sobre uma sociedade justa/socialista. O paradoxo emerge de uma tensão entre progresso e determinismo no segundo sonho da protagonista Vera Pavlovna: a moça pondera sobre a necessidade de um solo de boa qualidade para produzir uma colheita saudável, fazendo clara alusão ao contexto político de uma sociedade, isto é, pessoas éticas só podem surgir em condições políticas favoráveis - um regime não opressor e livre de corrupção. ${ }^{26}$ Porém, forçosamente Tchernichévski admite que de tempos em tempos é possível que seres exemplares surjam de condições desfavoráveis, do contrário, seria impossível pensar o progresso humano. Seria isso um exemplo de que o determinismo de Tchernichévski é atenuado? Ou apenas um erro teórico? Para tal discussão, é necessário conhecer seu principal romance.

\section{A "Nova Gente" ou Rakhmetov, quem responde à pergunta "o que fazer?"}

O que fazer? foi escrito no cárcere entre 1862 e 1863, considerada a Magnum opus de Tchernichévski. Nela, ele tenta agregar todos os aspectos do seu pensamento e ilustrá-lo por meio de um grupo de personagens. A história parece simples, de tema comum e desdenhada pelo próprio narrador do livro: "o tema do conto é o amor. A protagonista é uma mulher. Isso é bom, apesar do conto ser fraco - disse a leitora - É verdade disse eu". ${ }^{27}$ Esse mesmo narrador, contudo, faz questão de nos provocar constantemente nos chamando de "leitor perspicaz", como se quisesse estimular uma leitura que ultrapasse a superfície da obra, para compreender suas reais intenções.

A história inicia com um suicídio, cujos motivos não são explicados. Em seguida, somos apresentados à vida de três per-

26 Cf. TCHERNICHÉVSKI, 2017, p. 162-170.

27 Ibidem, p. 27. 
sonagens da "Nova Gente", que seriam os representantes da geração dos 60: jovens esclarecidos e materialistas que almejavam o progresso. São seres que não se encaixam na sociedade repressora na qual vivem, mas diferente dos "homens supérfluos" que permaneciam inoperantes em situações difíceis, estes não hesitavam diante das adversidades. Os três personagens são: Vera, Lopukhóv e Kirsánov. A primeira é uma jovem oprimida pela sua família burguesa, os outros dois são amigos estudantes de medicina. Lopukhóv, ciente da situação de Vera, planeja um casamento para "salvar" a jovem moça. Após o casamento, logo que percebe que o verdadeiro amor de Vera era seu amigo Kirsánov, Lopukhóv, em um ato "egoísta", mas racional, forja um suicídio para deixar o caminho livre à sua esposa. $O$ falso suicídio segue os critérios da teoria ética de Tchernichévski, uma vez que foi calculado para o bem-estar de Vera que, por consequência, seria o seu bem-estar. Esse ato egoísta é ainda bastante restrito e não podemos observar grandes implicações sociais - para dizer a verdade, apenas demonstra que a "Nova Gente" era capaz de abrir mão de seu prazer imediato se este beneficiasse um conjunto mais amplo de pessoas, aludindo àquela economia de afetos mencionada antes.

Uma construção mais social mediante o egoísmo racional poderá ser notada no ateliê de costura construído por Vera para obter sua independência. No ateliê, as jovens costureiras são ensinadas pelas mais velhas e todas dividem seus lucros, percebendo que elas eram mais bem remuneradas ali do que quando trabalhavam nas companhias privadas de seus patrões. Podemos deduzir que tal sociedade "justa e perfeita" que garantiria o bem-estar social era uma sociedade socialista aqui, claro, no modelo do socialismo utópico ${ }^{28} \mathrm{~A}$ obra aparenta ser apenas um elogio velado ao socialismo e à emancipação feminina, o que é notável considerando que é um romance do século XIX. A protagonista estava ciente de suas condições de mulher, como deixa muito claro: "Quase todos os caminhos da vida civil estão formalmente fechados, para nós, mulheres [...].

28 Não se pode confundir socialismo com marxismo. Não há dados biográficos que sugiram que Tchernichévski tenha lido Marx. 
De todas as esferas da vida, sobrou, para nós, apertarmo-nos na esfera da vida familiar: sermos membros da família e só isso". ${ }^{29}$

Exclusivamente por esses detalhes do romance, podemos notar como Tchernichévski estava distante dos temas em voga na literatura dos 40 . Lukács ${ }^{30}$, na sua "Introdução" à edição alemã ao romance, explica as substanciais diferenças entre essa obra e a literatura da geração dos 40 . Tchernichévski estava escrevendo conforme seus próprios critérios - vale lembrar que foi um importante crítico literário influenciado por Belínski -, seguindo as normas do realismo. A diferença entre o realismo e a literatura anterior pode ser notada pelos conflitos insolúveis de cunho individual e/ou psicológico. Em $O$ que fazer? o estudo psicológico de um personagem não é privilegiado, pois sua psique não estaria comprometida apenas com conflitos individuais. Existia um elemento trágico as voltas do herói psicológico, que termina sem solução em razão de sua miséria moral. A "Nova Gente", pelo contrário, podia e devia enfrentar tais conflitos racionalmente:

O novo homem pode resolver, sem enredo trágico e catástrofes, conflitos humanos semelhantes com o seu "egoísmo racional", o que torna evidente sua superioridade espiritual e moral. Isso significa que não existe nenhuma tragédia, na medida em que o homem agir no espírito do "egoísmo racional", na medida em que ele, com consciência límpida, examina seus próprios interesses (e produz uma organização racional deles), na medida em que ele, sem qualquer ilusão, sem qualquer fetiche, observa suas relações internas e externas. Mais corretamente: todo e qualquer conflito trágico que a estrutura social burguesa e a psicologia, moral, etc., que cresce nela, produz, não é de maneira nenhuma natureza "humana universal" (e não tem, portanto, nenhuma validade eterna). Elas são apenas formas de aparência da inumanidade, da estreiteza de espírito da sociedade burguesa, não sendo, assim, de modo algum definitivos, mas podem $\mathrm{e}$ devem ser superados. ${ }^{31}$

29 Ibidem, p. 331.

30 LUKÁCS, 2017.

31 Ibidem, p.17. 
Era mister a Tchernichévski que a arte expusesse as condições concretas da realidade. As adversidades enfrentadas por Vera, por exemplo, não eram decorrentes de sua fragilidade moral ou psicológica, mas sim das circunstâncias burguesas e autoritárias da Rússia tsarista. Por isso o autor tinha predileção por apresentar essas circunstâncias e não os fenômenos psicológicos. Na interpretação de G. Plekhanov: "Para Tchernichévski e para seu discípulo Dobroliúbov, a principal significação da arte consiste em reproduzir a vida e ajuizar de seus fenômenos" ${ }^{32}$ Em resumo: a arte deve ter serventia social, e isso significa que ela deve explicar a vida, instruir o leitor sobre a sociedade. ${ }^{33}$ Por isso o romance deve ser lido não apenas como um relato aos jovens revolucionários da época, mas como um manual didático sobre "o que fazer".

Esclarecidos os aspectos estéticos, podemos voltar à análise da história: Vera, ao descobrir a verdade sobre o suicídio de Lopukhóv, é tomada por profunda tristeza e decide abandonar o ateliê - e durante esse evento somos introduzidos a um personagem bastante peculiar no romance, o também estudante de medicina Rakhmetov. É ele quem conta a Vera toda a verdade sobre o suicídio, e também é ele que irá repreendê-la por desistir do ateliê.

Rakhmetov possuía hábitos incomuns e seguia um rígido código moral: "Não beberei nem uma gota de vinho. E não tocarei em nenhuma mulher" ${ }^{34} \mathrm{O}$ personagem é descrito como alguém que abdicava de qualquer prazer do corpo; quando comia carne, fazia apenas para fortalecer-se e reconhecia, com certa vergonha, seu único "vil prazer" sem o qual não conseguia pensar: charutos. Ele levava uma vida ascética para "[...] provar, com as nossas vidas, que exigimos isso, não para satisfação de nossas próprias paixões, não para nós próprios, mas para as pessoas em geral. Falamos por princípio e convicção,

32 PLEKHANOV, 1964, p. 4

33 Tchernichévski estava em conflito direto com a ideia de "arte pela arte", isto é, de que a arte deve apresentar apenas excelência estética, sendo privada de funções pedagógicas. As concepções estéticas do autor, que ele segue rigorosamente, foram apresentadas anos antes na sua dissertação "A relação estética entre arte e realidade" (1855).

34 TCHERNICHÉVSKI, 2017, p.260. 
não por paixão ou necessidade pessoal" ${ }^{35}$ Esse tipo de vida tem um propósito: preparar-se para a causa. O termo "causa" é adotado por Tchernichévski para substituir a "revolução". Por isso, podemos entender Rakhmetov como um indivíduo dedicado à revolução, mas tal dedicação é apresentada de maneira radical. Por exemplo, quando Rakhmetov dorme sobre uma cama de pregos - a princípio, podemos intuir que seja para saber se suportaria a dor que inevitavelmente acompanharia o processo revolucionário. De modo que é plausível afirmar que ele é o melhor exemplo do egoísta racional, considerando que aceitava um alto grau de dor para atingir o fim último do utilitarismo racional-egoísta.

Rakhmetov também repreende Vera por decidir abandonar seu ateliê, porque era "[...] a instituição que de maneira mais ou menos adequada correspondia aos ideais de uma forma de existência saudável, que servia de confirmação de sua viabilidade" ${ }^{36}$ Porém, seu julgamento sobre a responsabilidade da moça é mais brando, porque considerava que ela tomara tal atitude devido a uma profunda tristeza. Ora, significa que os eventos provocados por Lopukhóv desencadearam uma condição sentimental em Vera que a impediu de aplicar os princípios racionais sobre suas paixões. Nesse sentido, ele afirma ser Lopukhóv o maior responsável, uma vez que não soube conduzir a situação de maneira adequada e calma. ${ }^{37}$ Esse diálogo ilustra que nem mesmo a "Nova Gente", tipos esclarecidos e racionais, estavam livres de fracassos ou falhas. De certa maneira, isso já seria um argumento consistente para atestar que o determinismo racionalista de Tchernichévski não operava de modo tão acentuado como o "Princípio" faz parecer.

No entanto, esses fracassos podem ter sido inseridos na trama para demonstrar que esses tipos de pessoas não são utopias. A afirmação se sustenta pela função de Rakhmetov no romance. Segundo Tchernichévski, esse personagem caricato cumpre com a importante e essencial exigência da arte, que já

35 Ibidem, p. 260.

36 Ibidem, p. 281.

37 Cf. Ibidem, p. 286. 
mencionamos acima: expor a realidade como ela é e explicá-la: "é preciso descrever as coisas de modo que o leitor possa imaginá-las como elas realmente são". ${ }^{38}$ Basicamente, o personagem é um recurso literário em favor do realismo, isto é, da descrição das condições concretas do real. Ele diz que, para que possamos ver uma cabana como uma cabana, é inserido, a fim de comparação, um palácio, pois assim o leitor não iria se confundir. O receio do narrador era de que os leitores considerassem a "Nova Gente", os heróis principais do romance, como seres idealizados e, portanto, inexistentes ou impossíveis no real. A partir da comparação com Rakhmetov, a "Nova Gente" torna-se uma imagem mais verossímil, e disso se conclui que esses personagens não são muito elevados, mas nós é que os enxergamos assim porque estamos em um nível muito baixo.

Em vista de tais considerações, será Vera e não Rakhmetov que sonhará com a sociedade perfeita, em um episódio do romance que apresenta a mais nítida imagem sobre essa sociedade: a moça sonha com diferentes deusas, após encontrar deusas ainda subjugadas à sociedade patriarcal e opressora, Vera enxerga na última deusa ela mesma, agora emancipada e livre. Ela era a deusa da justiça e da igualdade, e quando indagada sobre onde morariam as pessoas após ela reinar sobre todos, a resposta é enfática:

Um edifício. Um imenso, enorme edifício como há poucos e apenas nas maiores capitais. Ou não? Na verdade, agora não há nenhum como esse. Ele eleva-se entre campos e prados, pomares e arvoredos. Os campos são nosso pão, mas não são como temos hoje. São espessos e abundantes. [...] Mas e esse edifício? O que é? Que tipo de arquitetura é essa? Hoje não há nada assim. Não, já há uma insinuação dele: o Palácio de Cristal, em Sidenham, apenas de ferro fundido e vidro, vidro e ferro fundido. ${ }^{39}$

Esse edifício faz referência ao Palácio de Cristal $^{40}$ o qual sim-

38 Ibidem, p. 291.

39 Ibidem, p. 344-345.

400 Palácio de Cristal do sonho de Vera para representar a sociedade socialista alude à construção erguida, primeiro, no Hyde Park, em Londres, para a Grande Exibição de 1851. Depois da exposição, foi reconstruído a Sydenham Hill. A Grande Exposição é um marco na história das ciências e da técnica e serviu para propagar os seus avanços. O Palácio 
bolizava a cidade ideal, justa e socialista na qual não haveriam mais desigualdades e o respeito mútuo entre seus habitantes imperava. O sonho de Vera é o sonho moderno e socialista de Tchernichévski: o fim último do progresso, uma sociedade fundada pela ciência e pela técnica, orientada em bases estritamente racionais. Porém, esse fim último não será atingido tão facilmente: é preciso tempo para que as pessoas possam perceber a grandiosidade da sociedade socialista e como ela é proveitosa. Muitas gerações serão necessárias para construi-la e Vera é alertada que não viveria o suficiente para aproveitá-la, mas, "pelo menos, viu-o [o Palácio]. Conhece o futuro. Ele é radioso, lindo. Diga a todos: eis o futuro e ele é radioso e lindo. Ame-o. Esforce-se por alcançá-lo. Trabalhe por ele. Faça-o ficar mais próximo. Transforme-o em presente tanto quanto possa". ${ }^{41}$ Nessa sociedade, a liberdade seria total, mas há uma ressalva. Essa "liberdade" seria possível porque, em uma sociedade esclarecida, os desejos e prazeres individuais convergiriam com os interesses coletivos, já que as ações são esclarecidas e motivadas pela natureza e por suas leis mecânicas, já que não haveria circunstância externa ocasionando qualquer impedimento à prática ética do egoísmo racional na sua plenitude. Logo, mesmo Tchernichévski admitindo uma sociedade livre, as circunstâncias sob as quais se circunscreve essa liberdade ainda acentuam o tom determinista de sua teoria.

Existem ainda outras dificuldades implicadas na concepção da sociedade socialista que não estão relacionadas ao conceito de liberdade. Por exemplo, a sua construção: Quem será responsável por erigir essa sociedade? É preciso refletir sobre o seguinte: se for tarefa à "Nova Gente", então aquela figura determinista e exacerbadamente racionalista de Rakhmetov

tornou-se assim a representação significado de "ser moderno": novo, imperioso, grandioso, avançado. Na Rússia, o impacto foi significativamente maior: "Para os russos da metade do século XIX, o palácio de Cristal foi um dos sonhos modernos mais constrangedores e inesquecíveis. 0 extraordinário impacto psíquico que teve sobre os russos - desempenha um papel muito mais importante na literatura e pensamento russos de que nos ingleses provém de sua função de espectro de modernização perseguindo toda uma nação que se contorcia convulsivamente na angústia do atraso (BERMAN, 1986, p. 224).

41 TCHERNICHÉVSKI, 2017, p. 363. 
foi apenas um recurso literário? Mesmo o "leitor perspicaz" do romance pode ficar confuso. Enquanto um manual sobre "o que fazer" - e considerando a "revolução" como resposta mais provável - é estranho pensar que o personagem que melhor exemplifica a ética tchernichevskiana, o modelo de revolucionário por excelência, seria desprezado em favor de iluminar a possibilidade de existência da "Nova Gente", pessoas "comuns" que, em determinadas situações, até comprometeram seus princípios e valores. ${ }^{42}$

Esse ponto é escorregadio e provoca embaraços. Uma sociedade justa e perfeita seria possível apenas mediante a revolução, e disso concluímos que seria Rakhmetov a peça fundamental na conquista dos objetivos socialistas, mas, então, qual o motivo desse personagem ser apresentado de forma quase fantástica na obra? ${ }^{43}$ Não há muito material no romance para extrair uma interpretação unilateral, mas é possível oferecer uma conclusão razoável sobre o personagem.

\section{Conclusão: Rakhmetov como expressão da revolução}

A problemática em relação ao determinismo de Tchernichévski está em torno de Rakhmetov. A tensão mencionada na segunda parte deste artigo, entre determinismo e razão, não é de grande dificuldade quando pensamos na "Nova Gente", porque eles assumem falhas, são personagens cujas ações não são determinadas de maneira tão perfeita como as de Rakhmetov, e tais falhas podem ser justificadas pelas condições do ambiente político e social em que se encontram. Porém, em Rakhmetov o paradoxo permanece: como pode um tipo tão

42 De fato, o personagem é controverso entre os críticos e leitores. Segundo DROZD (2012, p. 115) na época do romance, a maioria dos jovens russos ficaram mais impressionados com as aventuras de Vera e de seus dois maridos. Foram poucos os que tentaram conscientemente imitar Rakhmetov. Os detratores do romance, por sua vez, não tardaram em fazer uso dos exageros do personagem para justificar suas críticas negativas. Sobre a recepção do personagem pela crítica literária da época, conferir o capítulo 4 do livro Chernyshevskii's What is to be Done?: A Reevaluation (DROZD, 2012).

43 No próprio romance, uma pretendente de Rakhmetov, que ele recusa, chega a afirmar que "Em sonho, eu vejo-o cercado de um halo" (TCHERNICHÉVSKI, 2017, p. 269). 
extraordinário surgir em uma Rússia tão desfavorável? Como ele consegue agir de acordo com os mais elevados preceitos éticos do racionalismo egoísta, se vive em uma Rússia tomada pela corrupção, miséria e censura?

Esse problema pode sugerir diversas interpretações, por exemplo, Joseph Frank admite que o determinismo de Tchernichévski teve de ser contrariado - foi aberta uma exceção às leis da natureza - para ser possível surgir Rakhmetov, mas Frank considera que isso foi resultado mais da fragilidade teórica do filósofo russo do que de uma estratégia intelectual. ${ }^{44}$ Marcia Morris ${ }^{45}$, por sua vez, concede uma posição menos negativa, porém, sem estar livre de complicações. Em Saints and Revolutionaries, ela define Rakhmetov como um asceta extraordinário, isto é, um ser muito elevado e inatingível, porque representaria não o revolucionário ideal - como foi muito comum em interpretações soviéticas ${ }^{46}-$, mas a própria racionalidade incorporada que deveria ser unida à sociedade imperfeita e irracional. ${ }^{47}$ A Nova Gente, por outro lado, age a partir de um asceticismo moderno que não permite ações extremas, e, portanto, seus membros seriam apenas "reformadores sociais" [social reformer]. ${ }^{48}$ Morris argumenta que nada do que fora realizado pela Nova Gente era de grandes proporções - o ateliê de costura, a prática médica de Kirsánov, ou os aposentos compartilhados das famílias Kirsánov e Lopukhóv ${ }^{49}$, por exemplo. No entanto, existem dois problemas nessa interpretação: a primeiro depende da perspectiva pela qual compreendemos Rakhmetov: enquanto um asceta, ele é entendido quase que literalmente e suas ações, portanto, não são apenas metáforas - mesmo que a autora admita que Tchernichévski fez uso de recursos literários que tornassem possível o roman-

44 Cf. FRANK, 1992, p. 211.

45 Cf. MORRIS, 1993

46 Essa interpretação era bastante comum entre os intérpretes soviéticos. Sobre isso, Cf. DROZD, op. cit., p. 113-114.

47 Cf. MORRIS, op. cit., p. 139

48 Cf. Ibidem, p. 143.

49 Cf. Ibidem, p. 143 
ce ser aprovado pelos censores. Desse modo, fica à critério do leitor admitir se Rakhmetov é, de fato, aquele ser extraordinário, ou se ele é o recurso literário tal como foi apresentado pelo narrador. O segundo problema é mais objetivo: por mais importante que seja Rakhmetov, o personagem possui poucas aparições, pois os protagonistas são aqueles pertencentes à "Nova Gente". Logo, é pouco provável que um autor da geração dos 60 como Tchernichévski tenha criado protagonistas reformistas em um romance cujas pretensões são revolucionárias - como já elucidado, a geração dos 60 emerge em relação aos fracassos dos projetos reformistas antecessores.

Nesse sentido, a sugestão oferecida aqui é pensar a questão do determinismo a partir da revolução. Apesar de Rakhmetov fundir perfeitamente razão e vontade - mesmo antes da sociedade perfeita - há um determinado momento em que ele assume a característica de alguém de elevada sensibilidade. Isso acontece quando menciona sua alimentação: "se não está disponível para as pessoas simples, eu não devo comer. Tudo isso é preciso para que eu, pelo menos um pouco, sinta como a vida deles sofre limitações em comparação com a minha". ${ }^{50}$ Para levar adiante a revolução ele acolhe as dores da luta política, tendo a necessidade de sentir a diferença entre sua vida e a dos mais pobres, sentir suas dores. Mediante a afirmação de Rakhmetov, Tchernichévski está elucidando que de nada adianta projetos esclarecidos e esquemas lógicos bem estruturados, repleto de argumentos mais do que convincentes sobre a necessidade de um novo sistema de governo: só irá lutar por esse projeto aquele que sentir as dificuldades daqueles em circunstâncias desfavoráveis. Logo, é um afeto - e não um argumento lógico - que incita a luta pela transformação política da sociedade. Este é também um bom motivo para o autor inserir uma personagem feminina no centro do "Palácio de Cristal", uma vez que diferente de dois homens estudantes de medicina, a jovem Vera, mesmo de família burguesa, sentia o que era a desigualdade e indiferença.

50 TCHERNICHÉVSKI, op. cit., p. 261. 
Tchernichévski estava ciente de que um processo revolucionário exige muito esforço, porque uma revolução é dolorosa e violenta, de modo que o esclarecimento racional não seria suficiente. Segundo Norberto Bobbio, "revolução é a tentativa, acompanhada do uso da violência, de derrubar as autoridades políticas existentes e de as substituir, a fim de efetuar profundas mudanças nas relações políticas, no ordenamento jurídico-constitucional e na esfera sócio-economica". ${ }^{51} \mathrm{~A}$ definição do autor não é abstrata, pois considera as inúmeras experiências políticas em que é nítido como nenhum regime ou classe dominante aceitara mudanças no seu status e na sua estrutura sem opor resistência, e para tanto, não hesitam em fazer uso de seus dispositivos coercitivos. Logo, toda revolução implica resistência. A própria Rússia em que Tchernichévski viveu é exemplo da definição de Bobbio. Diante de tais considerações, considera-se que o mais importante na figura de Rakhmetov não é a do asceta ou a do modelo normativo e ideal de revolucionário, mas o ensinamento concreto de que a revolução é um processo doloroso e que jamais poderá ser suportado se o revolucionário não compartilhar, ao menos em parte, as dores do povo oprimido. A compreensão da opressão não pode ser apenas teórica, pois, do contrário, não poderia promover qualquer ação mais radical ou extrema. Rakhmetov, mais do que um modelo normativo, é a expressão da própria revolução e de suas dificuldades, sendo um "esclarecimento" que se dá através da sensibilidade a respeito da difícil tarefa que será imposta à "Nova Gente". Desse modo, o fato dele surgir em condições desfavoráveis não é um problema, pois não é a representação do ser ético, e sim a expressão das consequências de tais condições desfavoráveis quando motivadas pela dor compartilhada entre os indivíduos.

Infelizmente, em razão das condições sob as quais foi escrita, precisando burlar a censura, o romance possui diversas contradições que nem sempre podem ser esclarecidas de maneira conclusiva. Por outro lado, isso enriquece nossas interpretações. É preciso lembrar: Tchernichévski não pretende

51 Verbete "Revolução" In: BOBBIO, 1998, p. 1121, grifo nosso. 
explicar como fazer, mas - que pese o uso do clichê - o que fazer. E a resposta parece ser clara: revolução. Essa revolução não é realizada de maneira calculada - pois isso contraria os argumentos do "Princípio" -, apenas organizada pela razão. Há um importante fator sensível que a motiva. Essa interpretação é plausível porque ela não compromete os aspectos fundamentais da teoria de Tchernichévski: não é negado o papel da razão no esclarecimento de interesses naturais, nem mesmo o aspecto racional de uma teoria. $O$ intuito deste artigo é apontar que o determinismo de Tchernichévski não é tão intransigente quanto parece. Essa hipótese não se baseia, porém, na tensão entre o determinismo e progresso - tal como sugerem as interpretações de Morris e de Frank - e sim no conflito inerente à revolução entre sensibilidade e razão que está presente em Rakhmetov.

\section{Referências Bibliográficas}

BERMAN, M. Tudo o que é sólido se desmancha no ar. São Paulo: Companhia das Letras, 1986.

BOBBIO, N. Dicionário de Política. $11^{\mathrm{a}}$ ed. Tradução de Carmen C. Varille et. al. Brasília: Editora da UnB, 1998.

DOMINGUES, C. J. T. L. Nikolai Gavrílovitch Tchernichévski e a intelligentsia russa: filosofia e ética na segunda metade do século XX. Dissertação de Mestrado. Niterói, Universidade Federal do Fluminense, 2015.

DROZD, A. M. Chernyshevskii's "What is to Be Done": A Reevaluation. Evanston: Northwestern University Press, 2001.

FRANK, J. Pelo prisma russo. Tradução de Paula Cox Rolim e Francisco Achcar. São Paulo: Edusp, 1992.

FREDE, V. Doubt, atheism and the Nineteenth-Century Russian Intelligentsia. Madison: University of Wisconsin Press, 2011.

LUKÁCS, G. "Introdução à publicação alemã de $O$ que fazer? de Tchernichévski (1951)". Traduzido por Gabriel S. Philipson. ArteFilosofia, n. 22, Ouro Preto, 2017, p. 4-29. 
MORRIS, M. Saints and revolutionaries: The ascetic hero in Russian literature. Albany: State University of New York Press, 1993.

PLEKHANOV, G. Arte e vida social. Tradução de Eduardo Sucupira Filho. São Paulo: Brasiliense, 1964.

POLUNOV, Alexander. Russia in the nineteenth century: Autocracy, Reform and Social Chance, 1814-1914 (The New Russian History). New York: M.E. Sharpe, 2005.

SCANLAN, J. P. "Nicholas Chernyshevsky and philosopical Materialism in Russia", Journal of the History of Philosophy, v. 8, n. 1, Baltimore/Maryland, 1970, p. 65-86.

TCHERNICHÉVSKI, N. G. O que fazer?. Tradução de Angelo Segrillo. Lisboa: Guerra \& Paz Editores, 2017.

TCHERNICHÉVSKI, N. G. "The Anthropological Principle in Philosophy". In: Selected Philosophical Essays. Honolulu: University Press of the Pacific, 2002.

TURIN, S.P. Nicholas Chernyshevsky and John Stuart Mill. The Slavonic and East European Reviwe, v. 9, n. 25, 1930, p. 29-33.

WALICKI, Andrzej. A history of Russian thought: from the enlightenment to Marxism. Translated by Hilda Andrews-Rusiecka. California: Stanford University Press, 1979.

Recebido em: 22/05/2020

Aceito em: $19 / 07 / 2020$

Publicado em setembro de 2020 